\title{
Involvement of receptor-interacting protein 140 in palmitate-stimulated macrophage infiltration of pancreatic beta cells
}

\author{
RUNMEI ZOU ${ }^{1,2}$, JUNLI XUE ${ }^{1}$, QI HUANG ${ }^{1}$, ZHE DAI $^{1}$ and YANCHENG XU ${ }^{1}$ \\ ${ }^{1}$ Department of Endocrinology, Zhongnan Hospital of Wuhan University, Wuhan, Hubei 430071; \\ ${ }^{2}$ Children's Medical Center, The Second Xiangya Hospital of Central South University, Changsha, Hunan 410011, P.R. China
}

Received January 8, 2016; Accepted January 6, 2017

DOI: $10.3892 / \mathrm{etm} .2017 .4544$

\begin{abstract}
Receptor-interacting protein 140 (RIP140) in macrophages stimulates the nuclear factor- $\mathrm{\kappa B}$ subunit RelA to activate tumor necrosis factor (TNF)- $\alpha$ and interleukin (IL)-6 transcription. However, under lipotoxic conditions, the involvement of RIP140 in the infiltration of beta cells by macrophages remains unknown. In the present study, murine RAW264.7 macrophages were transfected with a RIP140 overexpression plasmid or siRNA prior to macrophage activation with $500 \mu \mathrm{M}$ palmitate. Palmitate-free conditioned media was then collected and added to murine insulinoma MIN6 cells. Significant decreases were observed in cell viability $(\mathrm{P}<0.01)$, glucose-stimulated insulin secretion $(\mathrm{P}<0.01)$ and levels of peroxisome proliferator-activated receptor- $\gamma$ coactivator-1 $\alpha(\mathrm{P}<0.05)$, phosphoenolpyruvate carboxykinase and proliferating cell nuclear antigen mRNA $(\mathrm{P}<0.01)$ in MIN6 cells. In addition, conditioned media from palmitate-treated and RIP140-upregulated macrophages significantly increased the levels of uncoupling protein-2 $(\mathrm{P}<0.01)$, inducible nitric oxide synthase $1(\mathrm{P}<0.01)$ and pancreatic and duodenal homeobox 1 $(\mathrm{P}<0.05)$ mRNA and levels of activated Jun $\mathrm{N}$-terminal kinase $(\mathrm{JNK})(\mathrm{P}<0.01)$ and extracellular signal-regulated kinase (ERK) $1 / 2(\mathrm{P}<0.01)$. In turn, the conditioned media was found to be significantly enriched in TNF- $\alpha$ and IL-6 (both $\mathrm{P}<0.05$ ). These results were the opposite of those obtained from MIN6 cells treated with conditioned media from palmitate-treated and RIP140-knockdown macrophages. MIN6 cells were transfected with RIP140 overexpression plasmid or siRNA prior to treatment with $500 \mu \mathrm{M}$ palmitate and supernatant was collected for use in macrophage chemotaxis assays. In the palmitate-activated and RIP140-overexpressing MIN6
\end{abstract}

Correspondence to: Professor Yancheng $\mathrm{Xu}$, Department of Endocrinology, Zhongnan Hospital of Wuhan University, 169 Donghu Road, Wuhan, Hubei 430071, P.R. China

E-mail: xj1100901@whu.edu.cn

Key words: macrophage infiltration, pancreatic beta cells, palmitate, receptor interacting protein 140 cells, TNF- $\alpha$ and IL-6 secretion increased significantly (both $\mathrm{P}<0.05)$ and macrophage chemotaxis towards MIN6 cells was enhanced. By contrast, downregulating RIP140 in MIN6 cells had the opposite effect. These data suggest that RIP140 in macrophages mediates the transcription of inflammatory cytokines when concentration of palmitate is high. Macrophage RIP140 may also impair beta cell function by activating the JNK and ERK1/2 signaling pathways and promoting specific gene transcription. Furthermore, expression of RIP140 in pancreatic beta cells may stimulate macrophage chemotaxis, thus triggering local low-grade inflammation.

\section{Introduction}

Dysfunction of pancreatic beta cells in type II diabetes is associated with high circulatory levels of free fatty acids and glucose. Previous results have demonstrated that levels of free fatty acids are higher in diabetic patients than in healthy individuals (1). High levels of saturated fatty acids, including palmitate, lauric acid and linoleic acids, activate signaling from toll like receptors (TLRs) and their downstream Jun N-terminal kinase (JNK) and nuclear factor- $\mathrm{\kappa B}(\mathrm{NF}-\kappa \mathrm{B})$ pathways, thus promoting the release of interleukin (IL)-6, tumor necrosis factor (TNF)- $\alpha$ and other inflammatory cytokines from macrophages $(2,3)$. An increase in fat mass associated with an inflammatory response may be involved in the development of insulin resistance, as indicated by a previous study in obese mice, where it was observed that an increased mass of adipose tissue led to macrophage infiltration of adipose tissue (4). Higher levels of circulating free fatty acids and inflammatory cytokines were also observed, which may then act on skeletal muscle cells, adipocytes and other cells to influence insulin signaling $(5,6)$. In muscle cells, the conditioned media from palmitate-stimulated macrophages has been demonstrated to activate protein kinase $\mathrm{C}-\theta$ and $-\varepsilon$ to promote inflammatory cytokine expression, thus contributing to insulin resistance (7) Conditioned media from palmitate-treated macrophages may also provoke insulin resistance in muscle cells at the levels of Akt signaling, glucose transporter type 4 translocation and glucose uptake (8). Furthermore, it has been observed in a co-culture of hepatocytes and macrophages that lipopolysaccharide-induced TNF- $\alpha$ factor (LITAF) was involved in macrophage infiltration of hepatocytes, with knockdown of 
LITAF leading to improvement of insulin resistance in human hepatocytes (9). Similarly, prolonged exposure of beta cells to inflammatory cytokines may induce excessive production of reactive oxygen species and endoplasmic reticulum stress, leading to cell apoptosis and a decrease in insulin secretion (10,11). Collectively, these data suggest that insulin signaling and beta cell function may be altered by inflammatory processes. However, the underlying mechanism for the effects of macrophage-derived conditioned media on beta cell function remains unknown.

Receptor interacting protein 140 (RIP140) was first identified as a co-repressor of the estrogen receptor (12), with high expression of RIP140 observed in reproductive (13) and metabolic tissues, including adipose, liver and muscular tissue (14). RIP140 is now an established co-repressor of various nuclear receptors, including the thyroid receptor, peroxisome proliferator activated receptor (PPAR) (15), liver X receptor (LXR)- $\alpha$ (16), glucocorticoid receptor (17) and retinoic acid receptor (18), whereby it regulates the transcription of genes involved in glucose and lipid metabolism (16). In some instances, RIP140 also acts as a co-activator of nuclear receptors, by stimulating histone acetylase and cyclic adenosine monophosphate-responsive element binding protein (CBP), as the co-activator of $\mathrm{NF}-\kappa \mathrm{B}$, thus promoting pro-inflammatory cytokine transcription (19). Intracellular cholesterol and a high fatty diet may increase the level of RIP140 in macrophages, whereas microRNA miR-33 reduces the inflammatory activity of macrophages by inhibiting RIP140 co-activation of NF- $\kappa$ B (20). It has been demonstrated that macrophage treatment with a low dose of lipopolysaccharide (LPS) stimulated phosphorylation of RIP140 by spleen tyrosine kinase, thus stimulating RIP140 interaction with the NF-kB subunit RelA. In turn, this triggered the degradation of RIP140, resulting in decreased transcription of cytokine genes and a reduced inflammatory response (21). Additionally, mice with RIP140 knockdown in macrophages exhibit a decreased population of circulating monocytes, along with a reduction in inflammatory M1 (pro-inflammatory phenotype) and expansion in M2 (anti-inflammatory phenotype) macrophages, which subsequently improved insulin resistance induced by a high-fat $\operatorname{diet}(22)$.

Co-activation of NF- $\kappa \mathrm{B}$ by RIP140 mediates the release of inflammatory cytokines. However, under lipotoxic conditions, the influence of RIP140 on the infiltration of pancreatic beta cells by macrophages and the subsequent effects on beta cell function remain unknown. In the present study, conditioned media from palmitate-stimulated macrophages was used to stimulate beta cells and the chemotaxis of macrophages towards beta cells was evaluated. It was determined that RIP140 promoted inflammatory cytokine expression in macrophages under high palmitate conditions and impaired beta cell function. In addition, under lipotoxic conditions, RIP140 enhanced the chemotaxis of macrophages towards pancreatic beta cells through the release of inflammatory cytokines, thus triggering local low-grade inflammation and impairing beta cell function.

\section{Materials and methods}

Materials and reagents. A total of $50 \mathrm{mM}$ palmitate (Sigma-Aldrich; Merck KGaA, Darmstadt, Germany) was dissolved in $1 \mathrm{ml}$ 99\% ethanol and mixed with $9 \mathrm{ml} 10 \%$ bovine serum albumin (BSA; Sigma-Aldrich; Merck KGaA), from which a $5 \mathrm{mM}$ palmitate-10\% BSA stock solution was prepared, as previously described (23). Antibodies against phosphorylated (p)-JNK (cat. no. 9255S), JNK (cat. no. 3708S), p-ERK1/2 (cat. no. 9106S) and ERK1/2 (cat. no. 4696S) were purchased from Cell Signaling Technology, Inc. (Danvers, MA, USA). Antibodies against RIP140 (cat. no. ab42125) and $\beta$-actin (cat. no. sc-130300) were purchased from Abcam (Cambridge, MA, USA) and Santa Cruz Biotechnology, Inc. (Dallas, TX, USA), respectively. Goat anti-rabbit immunoglobulin (Ig)-G (heavy and light chain) secondary antibody conjugated to horseradish peroxidase (HRP; cat. no. BS13278) was obtained from Bioworld Technology, Inc. (St. Louis Park, MN, USA). ELISA kits for mouse TNF- $\alpha$ (cat. no. EK0527) and IL-6 (cat. no. EK0411) were purchased from Wuhan Boster Biological Technology, Ltd. (Wuhan, China).

Cell culture and treatment. Murine RAW264.7 macrophages (American Type Culture Collection, Manassas, VA, USA) were maintained in RPMI 1640 medium supplemented with $10 \%$ fetal bovine serum (FBS; Hyclone; GE Healthcare, Logan, UT, USA) and $1 \%$ penicillin-streptomycin at $37^{\circ} \mathrm{C}$ in a humidified atmosphere $\left(5 \% \mathrm{CO}_{2}\right)$ for $24 \mathrm{~h}$. The mouse pancreatic beta cell line MIN6 (American Type Culture Collection) was cultured overnight in Dulbecco's modified Eagle medium (DMEM; Hyclone; GE Healthcare) supplemented with 10\% FBS (Gibco; Thermo Fisher Scientific, Inc. Waltham, MA, USA), $0.001 \%$ beta-mercaptoethanol and $1 \%$ penicillin-streptomycin at $37^{\circ} \mathrm{C}$ in a humidified atmosphere $\left(5 \% \mathrm{CO}_{2}, 95 \%\right.$ air). Macrophages were transiently transfected with pEGFP-N1-RIP140 plasmid (or pEGFP-N1 plasmid as a control) or RIP140 siRNA (or scramble siRNA as a control) at $37^{\circ} \mathrm{C}$ for $24 \mathrm{~h}$, then treated with $500 \mu \mathrm{M}$ palmitate at $37^{\circ} \mathrm{C}$ for $24 \mathrm{~h}$. Supernatant was then collected in order to detect the concentrations of TNF- $\alpha$ and IL- 6 using the relevant ELISA kits, according to the manufacturer's instructions. Macrophages were washed several times with phosphate-buffered saline (PBS) and fresh RPMI 1640 media with $10 \%$ FBS was added. Following $24 \mathrm{~h}$ incubation at $37^{\circ} \mathrm{C}$, palmitate-free conditioned media was collected, centrifuged (10,000 x g, $5 \mathrm{~min}$, room temperature) and added to MIN6 cells for a $24 \mathrm{~h}$ incubation, as previously described (7). MIN6 cells were then collected for cell viability, gene expression and western blot analyses. For chemotaxis assays, MIN6 cells were transiently transfected and treated with palmitate as above and culture supernatant was collected.

Plasmid construction and cell transfection. A mouse RIP140 overexpression plasmid was constructed, as previously described (24), for transfection into the RAW264.7 macrophages and MIN6 cells. Briefly, total DNA from RAW264.7 macrophages was extracted using a DNA extraction kit (cat. no. DP304; Beijing Transgen Biotech Co., Ltd., Beijing, China) and a fragment of RIP140 (Reference Sequence: NM 173440.2) was amplified by polymerase chain reaction (PCR) using the following primers: Forward, 5'-GACTCGAGG ATCTTACTGACGAGAGGAGCT-3', and reverse, 5'-ACG GTACCCAGGTACACATTTCTTCTGACTC-3'. A TransTaq High Fidelity DNA polymerase was obtained from Beijing 
Transgen Biotech Co., Ltd. (Beijing, China) and the cycling conditions were as follows: 4 cycles for $30 \mathrm{sec}$ each at $94^{\circ} \mathrm{C}$, 1 cycle for $30 \mathrm{sec}$ at $58^{\circ} \mathrm{C}, 1$ cycle for $4 \mathrm{~min}$ at $72^{\circ} \mathrm{C}, 30$ cycles for $30 \mathrm{sec}$ each at $94^{\circ} \mathrm{C}, 1$ cycle for $30 \mathrm{sec}$ at $64^{\circ} \mathrm{C}$ and $4 \mathrm{~min}$ at $72^{\circ} \mathrm{C}$. KpnI (GGTACC) and XhoI (CTCGAG) restriction sites were included to facilitate ligation of the cDNA product into a pEGFP-N1 plasmid (Biovector Science Lab, Inc., Beijing, China) using Kpn I, Xho I and T4 DNA ligase (all from Fermentas Inc., Burlington, Canada), according to the manufacturer's protocol. The sequence of pEGFP-N1-RIP140 was verified by DNA sequencing. The sequences of RIP140 siRNA were as follows: Forward, 5'-CGGCGUUGACAU CAAAGAAdTdT-3' and reverse, 3'-dTdTGCCGCAACUGU AGUUUCUU-5'. Transient transfection was conducted with Lipofectamine $^{\mathrm{TM}} 2000$ (Invitrogen; Thermo Fisher Scientific, Inc.) according to manufacturer's protocol. Lipofectamine 2000 and $250 \mu 1$ optimum-minimal essential medium (Opti-MEM; Gibco; Thermo Fisher Scientific, Inc.) were mixed, incubated at room temperature for $5 \mathrm{~min}$, then $5 \mu \mathrm{g}$ plasmid or $200 \mathrm{pmol} / \mathrm{l} \mathrm{siRNA}$ was added to a separate $250 \mu \mathrm{l}$ Opti-MEM. The two solutions were mixed and incubated for $20 \mathrm{~min}$ at room temperature, then added to serum-free medium-cultured RAW264.7 cells. The mixture was replaced with fresh medium after $6 \mathrm{~h}$ incubation at $37^{\circ} \mathrm{C}$.

Total RNA extraction and reverse transcription (RT)-PCR. Total RNA was extracted with a Spin Column RNA Extraction kit (Sangon Biotech Co., Ltd., Shanghai, China) and transcribed to cDNA using Moloney Murine Leukemia Virus reverse transcriptase (Promega Corporation, Madison, WI, USA). PCR for RIP140 was performed using a SYBR-Green PCR Master Mix kit (Takara Bio, Inc., Otsu, Japan), according to the manufacturer's protocol. The cycling conditions were as follows: An initial denaturation step at $95^{\circ} \mathrm{C}$ for $5 \mathrm{~min}$, followed by 40 PCR cycles for $5 \mathrm{sec}$ each at $95^{\circ} \mathrm{C}, 1$ cycle for $30 \mathrm{sec}$ at $58^{\circ} \mathrm{C}$ and 1 cycle for $30 \mathrm{sec}$ at $72^{\circ} \mathrm{C}$. Semiquantitative RT-PCR was performed using Taq DNA polymerase (Takara Bio, Inc.) for comparison of the cDNAs developed, under the following conditions: An initial denaturation at $95^{\circ} \mathrm{C}$ for $5 \mathrm{~min}$, followed by $30 \mathrm{PCR}$ cycles for $5 \mathrm{sec}$ each at $95^{\circ} \mathrm{C}, 1$ cycle for $30 \mathrm{sec}$ at $56^{\circ} \mathrm{C}$ and 1 cycle for $30 \mathrm{sec}$ at $72^{\circ} \mathrm{C}$. Semiquantification was performed using mouse $\beta$-actin as an internal standard. Levels of target bands in the agar gel were analyzed by AlphaEaseFC 4.0 software (Alpha Innotech Corporation; ProteinSimple, San Jose, CA, USA), The primers of all genes quantified are listed in Table I.

Western blotting. MIN6 cells were washed three times with PBS and lysed on ice in radioimmunoprecipitation assay buffer containing $50 \mathrm{mM}$ Tris hydrochloride (pH 7.4), $150 \mathrm{mM}$ sodium chloride (NaCl), 1\% NP-40 lysis buffer, $0.1 \%$ SDS, $1 \mathrm{mM}$ phenylmethylsulfonyl fluoride and $1 \mathrm{mM}$ phosphatase inhibitor (Applygen Technologies Inc, Beijing, China) for $30 \mathrm{~min}$, then centrifuged at $10,000 \mathrm{x}$ at $4^{\circ} \mathrm{C}$ for $10 \mathrm{~min}$. The supernatant was collected and protein concentration was determined using a BCA Protein Assay kit (Applygen Technologies, Inc., Beijing, China), according to the manufacturer's protocol. SDS-PAGE, trans-blotting and subsequent immunodetection were performed, as previously described (25). Briefly, blots were incubated with primary antibodies (anti-RIP40, 1:1,000;
anti-p-JNK, 1:250; and anti-JNK, anti-p-ERK and anti-ERK, $1: 500)$ at $4{ }^{\circ} \mathrm{C}$ overnight, then with HRP-conjugated secondary $\operatorname{IgG}(1: 5,000)$ at $37{ }^{\circ} \mathrm{C}$ for $1 \mathrm{~h}$. $\beta$-actin was used as an internal control. Levels of target protein within bands were determined using AlphaEaseFC 4.0 software.

Cell viability. MIN6 cells $\left(5 \times 10^{3}\right.$ cells/ per well) were cultured in 96 well plates in complete DMEM at $37^{\circ} \mathrm{C}$. After $24 \mathrm{~h}$ of culture, cells were treated with $100 \mu \mathrm{l}$ conditioned media from the following RAW264.7 cells: i) Treated with BSA, ii) treated with $500 \mu \mathrm{M}$ palmitate, iii) transfected with pEGFP-N1 control plasmid, iv) transfected with pEGFP-N1-RIP140 plasmid, v) transfected with scramble siRNA and vi) transfected with RIP140 siRNA. Groups 3-6 were treated with $500 \mu \mathrm{M}$ palmitate for $24 \mathrm{~h}$ post-transfection. Cell viability was then measured by a 3-(4,5-Dimethylthiazol-2-yl)-2,5-diphenyltetrazolium bromide (MTT) assay. Specifically, $5 \mathrm{mg} / \mathrm{ml}$ MTT solution (Sigma-Aldrich; Merck KGaA) was added to each well prior to $4 \mathrm{~h}$ incubation at $37^{\circ} \mathrm{C}$. The resulting formazan precipitate was dissolved by adding $100 \mu \mathrm{l}$ dimethyl sulfoxide (Sigma-Aldrich; Merck KGaA) for $10 \mathrm{~min}$ at room temperature. Color intensity was then detected at $570 \mathrm{~nm}$ by a microplate reader (Thermo Labsystems, Beverly, MA, USA). Three independent experiments were performed.

Glucose-stimulated insulin secretion assay. MIN6 cells were exposed to the conditioned media of RAW264.7 cells for $24 \mathrm{~h}$. MIN6 cells were then washed twice with PBS, incubated in Krebs-Ringer bicarbonate 4-(2-hydroxyethyl)-1-piperazineethanesulfonic acid (HEPES) buffer (KRBH buffer: $115 \mathrm{mM} \mathrm{NaCl}, 24 \mathrm{mM}$ sodium bicarbonate, $5 \mathrm{mM}$ potassium chloride, $1 \mathrm{mM}$ magnesium chloride, $25 \mathrm{mM}$ HEPES, $0.5 \%$ BSA, pH 7.4) with $2.8 \mathrm{mM}$ glucose for $40 \mathrm{~min}$. Supernatant was then collected for measurement of basal insulin secretion (BIS). Fresh KRBH buffer containing $25 \mathrm{mM}$ glucose was added to MIN6 cells and cells were incubated at $37^{\circ} \mathrm{C}$ for $60 \mathrm{~min}$. Supernatant was then collected to measure glucose-stimulated insulin secretion (GSIS). Insulin concentrations were measured with an ELISA kit (cat. no. CSB-E05071m; Cusabio Biotech Co., Ltd., Wuhan China), according to the manufacturer's protocol. The experiment was performed three times.

Chemotaxis assays. Chemotaxis assays were performed on Transwell plates (24-well format, $8 \mu \mathrm{m}$; Corning Incorporated, Corning, NY, USA). A total of $500 \mu \mathrm{l}$ conditioned media from MIN6 cells was added to the lower chamber. RAW264.7 cells were washed with PBS three times and suspended in RPMI 1640 medium containing $0.5 \%$ FBS, then seeded into the upper chamber $\left(10^{4}\right.$ cells in total). Chambers were incubated for $6 \mathrm{~h}$ at $37^{\circ} \mathrm{C}$. Cells that remained in the upper chamber were removed while cells in the lower chamber were fixed with $4 \%$ paraformaldehyde for $20 \mathrm{~min}$ at room temperature, followed by incubation with $1 \%$ crystal violet (Sigma-Aldrich; Merck $\mathrm{KGaA}$ ) for $10 \mathrm{~min}$ at room temperature. Stained cells were manually counted under a light microscope in 6 randomly selected fields. The experiment was performed three times.

Chemotaxis of murine peritoneal macrophages was also measured. Peritoneal macrophages were isolated from 3 male c57BL/6 mice obtained from the Animal Center of Wuhan 
University, Wuhan, China (mean age, $5.0 \pm 0.5$ weeks; mean weight, $19.0 \pm 0.5 \mathrm{~g})$. The research protocol was approved by Medical Ethical Committee of Zhongnan Hospital (Wuhan, China). The mice were sacrificed by cervical dislocation and soaked in $75 \%$ ethyl alcohol for $5 \mathrm{~min}$, injected intraperitoneally with $5 \mathrm{ml}$ serum-free RPMI 1640 medium, then placed in a supine position for $5 \mathrm{~min}$. The abdominal cavity was opened and $5 \mathrm{ml}$ peritoneal fluid was aspirated and centrifuged at $1,000 \mathrm{x} \mathrm{g}$ at $4^{\circ} \mathrm{C}$ for $5 \mathrm{~min}$. Isolated cells were maintained in RPMI1640 medium supplemented with $10 \% \mathrm{FBS}$ at $37^{\circ} \mathrm{C}$ for $24 \mathrm{~h}$. After adhering to the culture dishes, macrophages were harvested and added to the upper Transwell chamber and conditioned media from MIN6 cells was added to the lower chamber. Chambers were incubated for $6 \mathrm{~h}$ at $37^{\circ} \mathrm{C}$ and chemotaxis assays were performed as before.

Statistical analysis. Data are presented as the mean \pm standard deviation. When two groups were being compared, differences between mean values were determined by Independent Sample $t$ tests. One-way analysis of variance followed by a Turkey test was used to determine differences between the mean values of $>2$ groups. Statistical analysis was performed using SPSS 17.0 (SPSS, Inc. Chicago, IL, USA) and $\mathrm{P}<0.05$ was considered to indicate a statistically significant difference.

\section{Results}

TNF- $\alpha$ and IL- 6 levels are elevated by RIPI40 in palmitate-treated macrophages. Expression of RIP140,TNF- $\alpha$ and IL- 6 at the mRNA and protein level in palmitate-treated RAW264.7 macrophages was determined by semiquantitative RT-PCR and ELISA, respectively. It was observed that the level of RIP140 mRNA expression in RAW264.7 cells was significantly increased by $500 \mu \mathrm{M}$ palmitate, compared with control cells treated with BSA alone $(\mathrm{P}<0.05$; Fig. 1A). Expression of the inflammatory cytokines TNF- $\alpha$ and IL- 6 was also significantly increased at the mRNA and protein levels by $250 \mu \mathrm{M}$ and $500 \mu \mathrm{M}$ palmitate, relative to control cells. Relative to $250 \mu \mathrm{M}$ palmitate, expression of TNF- $\alpha$ and IL- 6 was also significantly increased at the mRNA and protein levels by $500 \mu \mathrm{M}$ palmitate $(\mathrm{P}<0.05$; Fig. $1 \mathrm{~B}-\mathrm{E})$. The level of RIP140 expression was subsequently regulated by transfection of RAW264.7 macrophages with RIP140 plasmid or siRNA. As demonstrated by western blot analysis, the level of RIP140 protein expression was significantly increased in cells transfected with pEGFP-N1-RIP140 plasmid, relative to wild type control cells $(\mathrm{P}<0.05$; Fig. $2 \mathrm{~A}$ and $\mathrm{B})$. In addition, transfection with RIP140 siRNA significantly decreased RIP140 mRNA, relative to control cells transfected with scramble siRNA $(\mathrm{P}<0.05$; Fig. $2 \mathrm{C}$ and $\mathrm{D})$. The influence of these transfections on inflammatory cytokine expression in palmitate-treated macrophages was subsequently evaluated. In RAW264.7 macrophages treated with $500 \mu \mathrm{M}$ palmitate, it was observed that the expression of TNF- $\alpha$ and IL- 6 were significantly increased at the mRNA and protein levels by the RIP140 overexpression plasmid, relative to control cells transfected with pEGFP-N1 plasmid alone ( $\mathrm{P}<0.01$; Fig. 3). In addition, TNF- $\alpha$ and IL- 6 expression was significantly decreased by RIP140 siRNA, relative to scramble siRNA control cells $(\mathrm{P}<0.01$; Fig. 3$)$. These data suggest that RIP140
Table I. Primer sequences.

\begin{tabular}{ll}
\hline Genes (accession no.) & \multicolumn{1}{c}{ Primer sequences (5' to 3') } \\
\hline $\begin{array}{l}\text { RIP140 (NM 73440.2) } \\
\text { Forward }\end{array}$ & \\
& GGCAGCAAACCTGAATTC \\
Reverse & GGC \\
$\beta$-actin (NM 0007393.3) & \\
Forward & TCTACAATGAGCTGCGTGTG \\
Reverse & GGTGAGGATCTTCATGAGGT \\
TNF- $\alpha$ (NM 013693.2) & \\
Forward & CCACCACGCTCTTCTGTCTAC \\
Reverse & TGGGCTACAGGCTTGTCACT
\end{tabular}

\section{IL-6 (NM 031168.1)}

Forward

Reverse

CCACTTCACAAGTCGGAGGC TTA

GCAAGTGCATCATCGTTGTTC ATAC

PGC-1 $\alpha$ (NM 008904.2)

Forward

Reverse

PEPCK (NM 011044.2)

Forward

Reverse

PDX-1 (NM 008814.3)

Forward

Reverse

PCNA (NM 011045.2)

Forward

Reverse

GTGTTCCCGATCACCATATTCC CGGTGTCTGTAGTGGCTTGA TTC

ATCTTTGGTGGCCGTAGACCT GCCAGTGGGCCAGGTATTT

GATGAAATCCACCAAAGCTCA

AGAATTCCTTCTCCAGCTCCA

TCGACACATACCGCTGCGACC

GCAAATTCACCCGACGGCATC

UCP-2 (NM 011671.4)

Forward

Reverse

iNOS1 (NM 010927.3)

Forward

GCATTGGCCTCTACGACTCT

CTGGAAGCGGACCTTTACC

\section{AATGGCAACATCAGGTCGGC \\ CATCACT \\ GCTGTGTGTCACAGAAGTCTC GAACTC}

Reverse

RIP140, receptor interacting protein 140 ; TNF- $\alpha$, tumor necrosis factor- $\alpha$; IL-6, interleukin-6; PGC-1 $\alpha$, pepsinogen C; PEPCK, phosphoenolpyruvate carboxykinase; PDX-1, pancreatic and duodenal homeobox 1; PCNA, proliferating cell nuclear antigen; UCP-2, uncoupling protein-2; iNOS1, nitric-oxide synthase 1 .

promotes TNF- $\alpha$ and IL-6 expression in macrophages in high palmitate conditions.

Conditioned media from macrophages modifies cell viability. Conditioned media collected from palmitate-treated RAW264.7 macrophages (500 $\mu \mathrm{M}$ palmitate) was added to MIN6 pancreatic beta cells and cell viability was measured by an MTT assay. It was observed that cell viability was significantly reduced by 

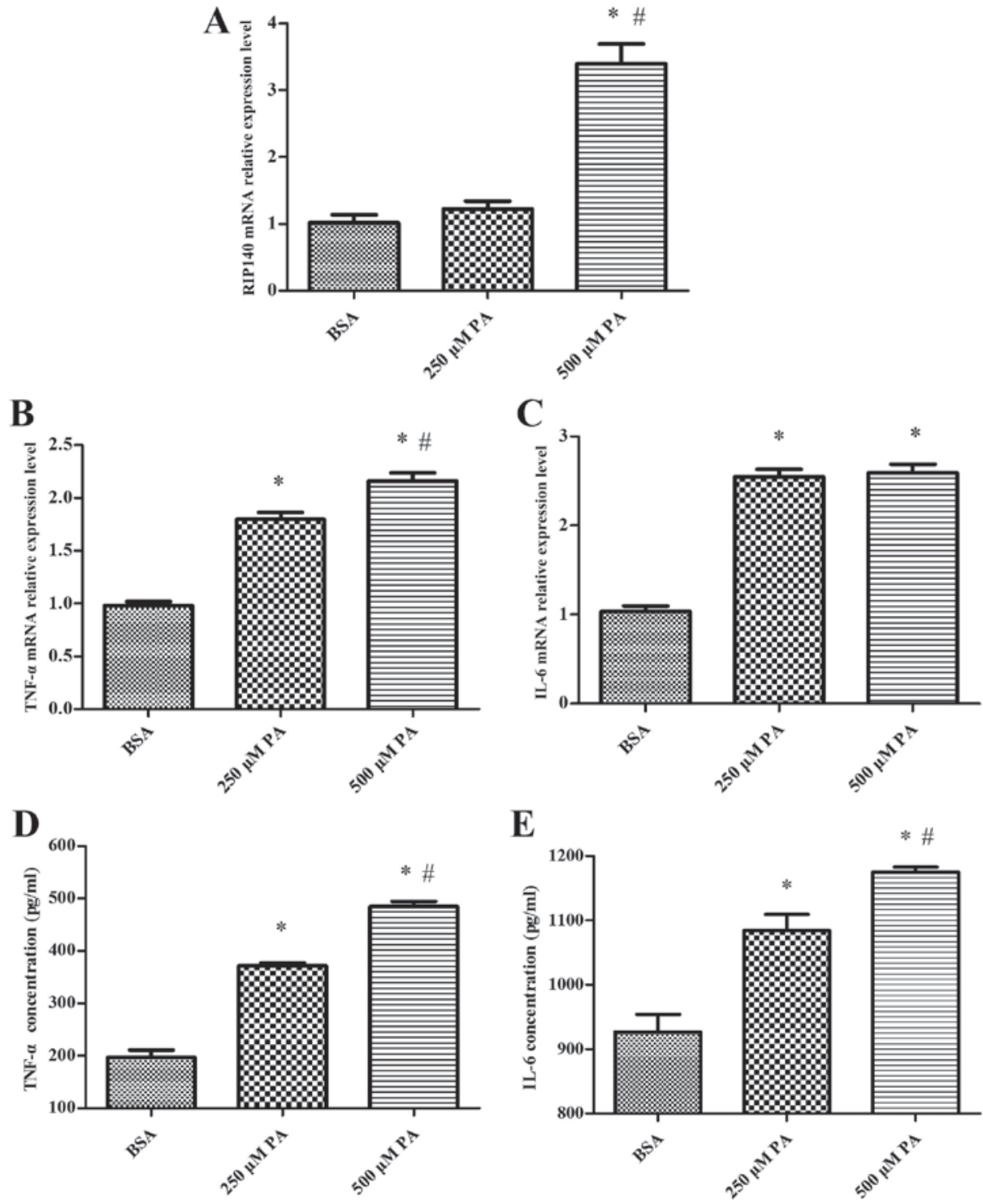

Figure 1. Palmitate induced the expression of RIP140 and inflammatory cytokines in RAW264.7 macrophages. RAW 264.7 cells were treated with BSA, 250 or $500 \mu \mathrm{M}$ palmitate for $24 \mathrm{~h}$ and the levels of (A) RIP140, (B) TNF- $\alpha$ and (C) IL-6 mRNA expression were determined by semiquantitative reverse transcription polymerase chain reaction. The concentrations of (D) TNF- $\alpha$ and (E) IL-6 in the RAW264.7 cell culture supernatant were determined by ELISA. Data are presented as the mean \pm standard deviation of three independent experiments. "P $<0.05$ vs. BSA, ${ }^{\prime \prime} \mathrm{P}<0.05$ vs. $250 \mu \mathrm{M}$ PA. BSA, bovine serum albumin; PA, palmitate; RIP140, receptor-interacting protein 140; TNF- $\alpha$, tumor necrosis factor- $\alpha$; IL-6, interleukin-6.

conditioned media from palmitate-treated RAW264.7 cells at 24 and $48 \mathrm{~h}$ post-media treatment, relative to media from control BSA-treated RAW264.7 cells ( $\mathrm{P}<0.05$; Fig. 4). It was also demonstrated that the viability of MIN6 cells was significantly decreased by conditioned media from palmitate-treated RAW264.7 cells transfected with RIP140 overexpression plasmid at 24 and $48 \mathrm{~h}$ post-treatment, relative to media of palmitate-treated RAW264.7 cells transfected with pEGFP-N1 plasmid alone $(\mathrm{P}<0.01$; Fig. 4). By contrast, conditioned media of palmitate-treated RAW264.7 cells transfected with RIP140 siRNA significantly increased MIN6 cell viability at 24 and $48 \mathrm{~h}$ post-media treatment, relative to media from control palmitate-treated RAW264.7 cells transfected with scramble siRNA $(\mathrm{P}<0.01$; Fig. 4).

Conditioned media modifies insulin secretion in MIN6 cells. Levels of GSIS and BIS in MIN6 cells treated with conditioned media from RAW264.7 macrophages prior to palmitate treatment were measured by ELISA. As depicted in Fig. 5, it was observed that GSIS was significantly decreased by conditioned media from palmitate-treated RAW264.7 cells, relative to the media of control RAW264.7 cells $(\mathrm{P}<0.01$; Fig. 5A). However, the insulin secretion index (ISI; defined as GSIS/BIS) did not differ significantly ( $\mathrm{P}=0.121$; Fig. 5B). This suggests that pancreatic beta cells may increase insulin secretion with short-term increases in levels of free fatty acids by a compensatory mechanism.

It was also demonstrated that GSIS and ISI in MIN6 cells were significantly decreased by conditioned media from RAW264.7 cells transfected with RIP140 overexpression plasmid, relative to media of RAW264.7 cells transfected with pEGFP-N1 plasmid alone $(\mathrm{P}<0.01$; Fig. 5). By contrast, GSIS and ISI were significantly increased by conditioned media from RIP140-knockdown RAW264.7 cells ( $\mathrm{P}<0.01$ and 
A
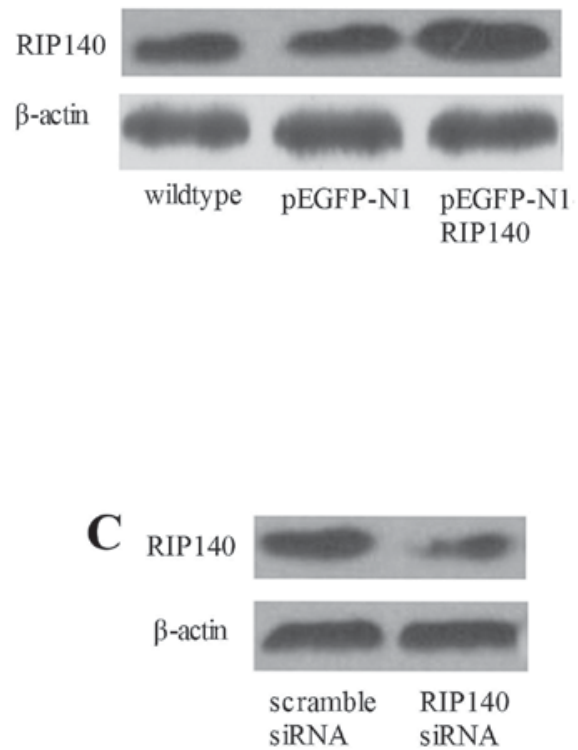
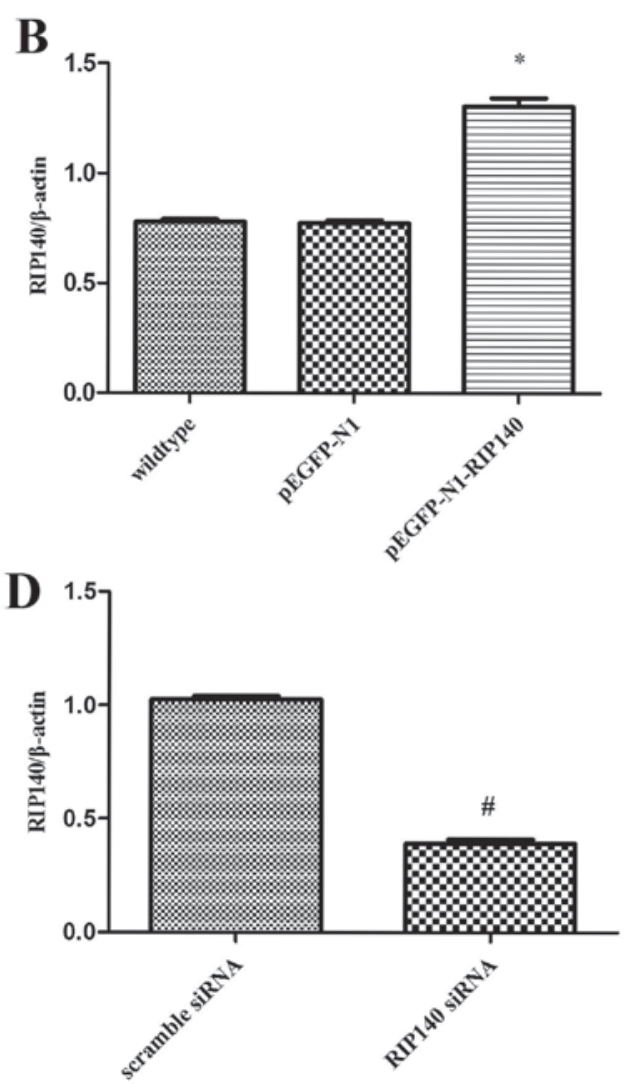

Figure 2. Level of RIP140 protein expression in RAW264.7 macrophages. RAW264.7 cells were transfected with (A and B) RIP140 overexpression plasmid or (C and D) RIP140 siRNA for $48 \mathrm{~h}$ and the level of RIP140 protein expression was determined by western blotting. $\beta$-actin was used as an internal control. Levels of target protein bands were quantified by AlphaEaseFC 4.0 software. Data are presented as the mean \pm standard deviation of three independent experiments. ${ }^{*} \mathrm{P}<0.05$ vs. pEGFP-N1, ${ }^{\text {P }}<0.05$ vs. scramble siRNA. RIP140, receptor-interacting protein 140; siRNA, small interfering RNA; pEGFP-N1-RIP140; RIP140 overexpression plasmid; pEGFP-N1, control plasmid.

$\mathrm{P}<0.05$, respectively), relative to media of RAW264.7 cells transfected with scramble siRNA (Fig. 5).

Conditioned media modifies specific gene expression in MIN6 cells. To identify the effects of the conditioned media from palmitate-treated RAW264.7 macrophages on pancreatic beta cell function, the levels of mRNA for oxidative stress-related genes, namely PPAR $\gamma$ coactivator $1 \alpha$ (PGC-1 $\alpha$ ), uncoupling protein 2 (UCP-2), nitric-oxide synthase 1 (iNOS1), insulin secretion related gene pancreatic and duodenal homeobox 1 (PDX-1), hepatic gluconeogenesis-related phosphoenulpyruvate carboxykinase (PEPCK) and proliferating cell nuclear antigen (PCNA) were determined by semiquantitative RT-PCR. It was observed that treatment with conditioned media from palmitate-treated RAW264.7 cells overexpressing RIP140 led to a significant downregulation in the levels of PGC-1 $\alpha(\mathrm{P}<0.05)$, PEPCK $(\mathrm{P}<0.05)$ and PCNA $(\mathrm{P}<0.01)$ mRNA in MIN6 cells, while significant upregulation in the mRNA of UCP-2 $(\mathrm{P}<0.01)$, iNOS1 $(\mathrm{P}<0.01)$ and PDX-1 $(\mathrm{P}<0.05)$ was observed. However, in MIN6 cells treated with media from palmitate-treated, RIP140-knockdown RAW264.7 cells, significant decreases were observed in the levels of PGC- $1 \alpha(\mathrm{P}<0.05)$, PEPCK $(\mathrm{P}<0.05)$ and PCNA $(\mathrm{P}<0.01)$ mRNA were significantly increased, while levels of UCP-2 $(\mathrm{P}<0.01)$, iNOS1 $(\mathrm{P}<0.05)$ and PDX-1 $(\mathrm{P}<0.05)$ mRNA (Fig. 6). These results suggest that conditioned media from palmitate-treated macrophages influences the transcription of genes associated with oxidative stress, insulin secretion and glucose metabolism in pancreatic beta cells.

Conditioned media modifies JNK and ERK1/2 phosphorylation in MIN6 cells. Levels of p-JNK and p-ERK1/2 in MIN6 cells treated with conditioned media were measured by western blotting. As depicted in Fig. 7, it was demonstrated that conditioned media from palmitate-treated macrophages stimulated a significant increase in JNK and ERK1/2 phosphorylation, relative to conditioned media from control RAW264.7 macrophages $(\mathrm{P}<0.01)$. It was also demonstrated that levels of $\mathrm{p}-\mathrm{JNK}$ and p-ERK 1/2 were significantly increased in MIN6 cells by the conditioned media of palmitate-treated RAW264.7 cells transfected with RIP140 overexpression plasmid, relative to the media of RAW264.7 cells transfected with pEGFP-N1 plasmid alone $(\mathrm{P}<0.01$; Fig. 7). By contrast, levels of p-JNK and p-ERK $1 / 2$ were significantly decreased by the conditioned media of palmitate-treated, RIP140-knockdown RAW264.7 cells, relative to the media of control RAW264.7 cells transfected with scramble siRNA (P<0.01; Fig. 7).

Macrophages chemotax towards MIN6 cells. Chemotaxis of murine macrophages (RAW264.7 and peritoneal) towards MIN6 cells following treatment with conditioned media from palmitate-treated MIN6 cells ( $500 \mu \mathrm{M}$ palmitate), was determined by Transwell assays (Fig. 8A and B). For RAW264.7 
A
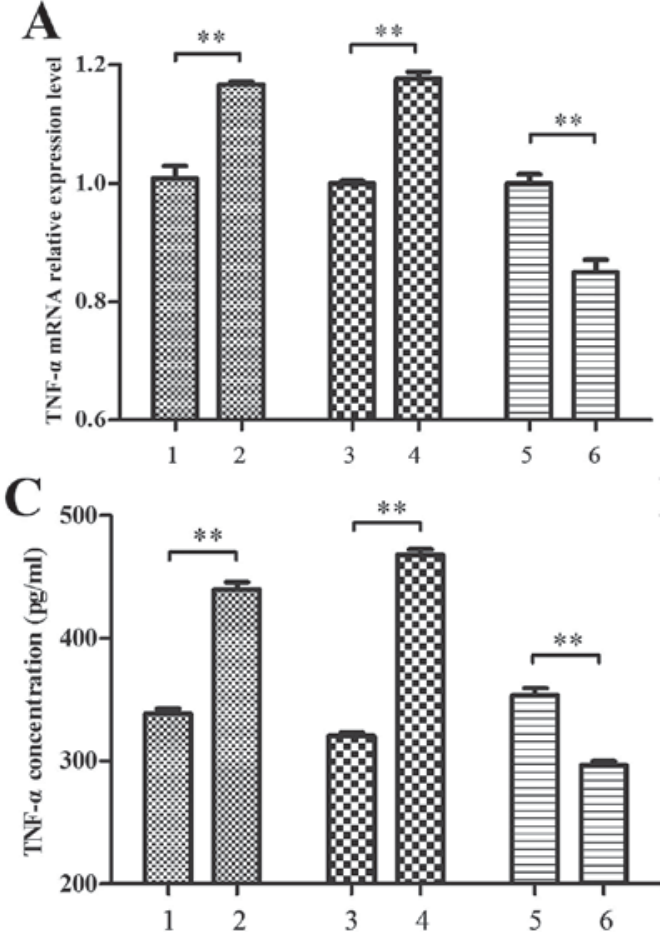

B

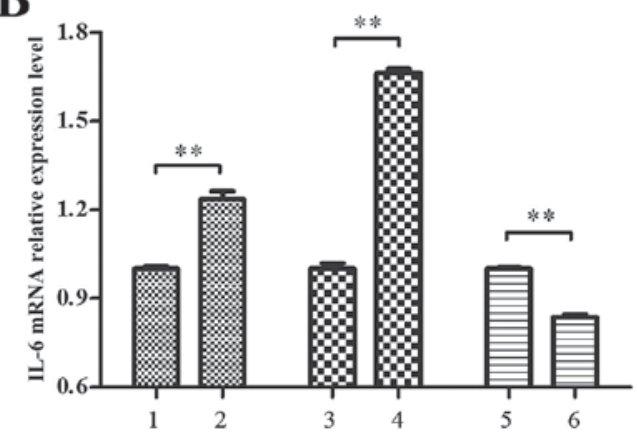

D

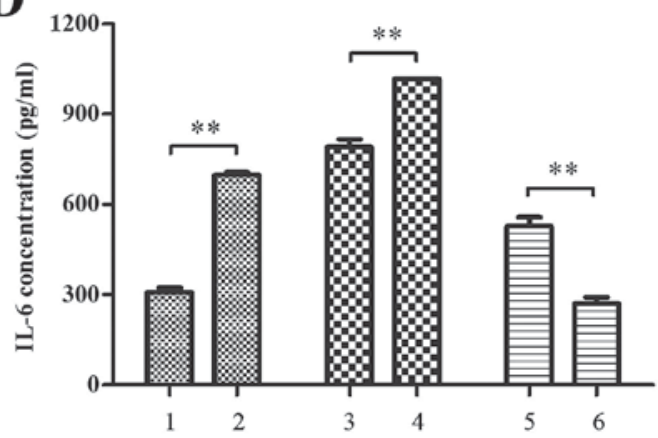

Figure 3. Palmitate promotes inflammatory cytokine expression via RIP140 in RAW264.7 macrophages. Levels of (A) TNF- $\alpha$ and (B) IL-6 mRNA expression were measured by semiquantitative reverse transcription polymerase chain reaction and the concentrations of (C) TNF- $\alpha$ and (D) IL-6 in RAW264.7 cell culture supernatant were determined by ELISA. The data represents the following experimental groups: i) RAW264.7 cells treated with bovine serum albumin, ii) RAW264.7 cells treated with $500 \mu \mathrm{M}$ palmitate, iii) RAW264.7 cells transfected with pEGFP-N1 control plasmid, iv) RAW264.7 cells transfected with pEGFP-N1-RIP140 plasmid, v) RAW264.7 cells transfected with scramble siRNA and vi) RAW264.7 cells transfected with RIP140 siRNA. Groups 3-6 were treated with $500 \mu \mathrm{M}$ palmitate post-transfection. Data are presented as the mean \pm standard deviation of three independent experiments. ${ }^{* * *} \mathrm{P}<0.01$. RIP140, receptor-interacting protein 140 ; TNF- $\alpha$, tumor necrosis factor- $\alpha$; IL-6, interleukin- 6 siRNA, small interfering RNA.

A

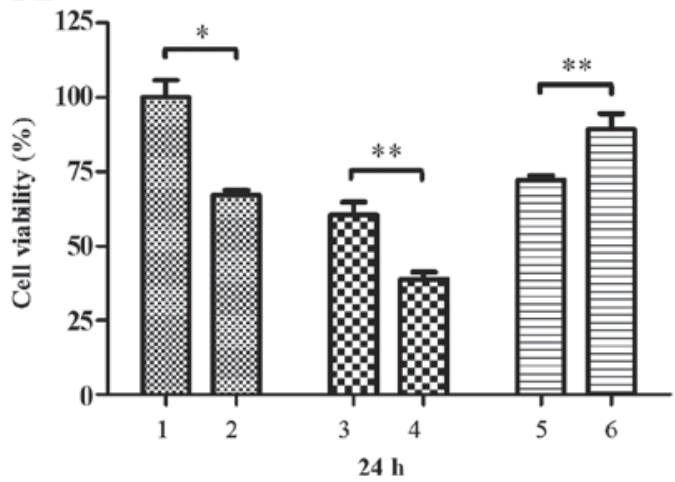

B

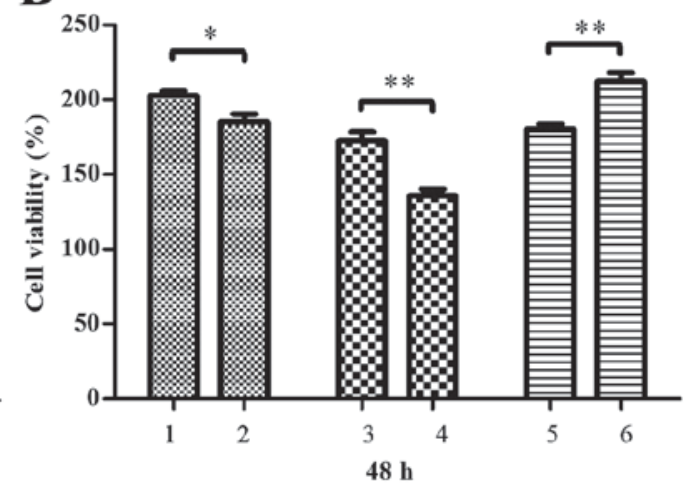

Figure 4. Conditioned media altered macrophage viability. MIN6 cells were incubated with conditioned media from RAW264.7 macrophage cultures and cell viability at (A) $24 \mathrm{~h}$ and (B) $48 \mathrm{~h}$ was determined by an MTT assay. Cell viability was measured relative to that of MIN6 cells $24 \mathrm{~h}$ after incubation with conditioned media from control macrophages treated with BSA. MIN6 cells were incubated with conditioned media obtained from the following: i) RAW264.7 cells treated with BSA, ii) RAW264.7 cells treated with $500 \mu \mathrm{M}$ palmitate, iii) RAW264.7 cells transfected with pEGFP-N1 control plasmid, iv) RAW264.7 cells transfected with pEGFP-N1-RIP140 plasmid, v) RAW264.7 cells transfected with scramble siRNA and vi) RAW264.7 cells transfected with RIP140 siRNA. Groups 3-6 were treated with $500 \mu \mathrm{M}$ palmitate post-transfection. Data are presented as the mean \pm standard deviation of three independent experiments. ${ }^{*} \mathrm{P}<0.05,{ }^{* *} \mathrm{P}<0.01$. MIN6, murine pancreatic beta cell line; BSA, bovine serum albumin; siRNA, small interfering RNA.

macrophages, it was observed that cell chemotaxis towards MIN6 cells was significantly increased by conditioned media from palmitate-treated MIN6 cells, relative to media from control BSA-treated MIN6 cells ( $\mathrm{P}<0.01$; Fig. 8C). It was also demonstrated that RAW264.7 cell chemotaxis was significantly increased by conditioned media from palmitate-treated MIN6 cells transfected with RIP140 overexpression plasmid, relative to media from palmitate-treated MIN6 cells transfected with pEGFP-N1 plasmid alone $(\mathrm{P}<0.01$; Fig. $8 \mathrm{C})$. By contrast, RAW264.7 cell chemotaxis was significantly decreased by the conditioned media of palmitate-treated, RIP140 siRNA-knockdown MIN6 cells, relative to the media of palmitate-treated MIN6 cells transfected with scramble siRNA ( $\mathrm{P}<0.01$; Fig. 8C). 
A

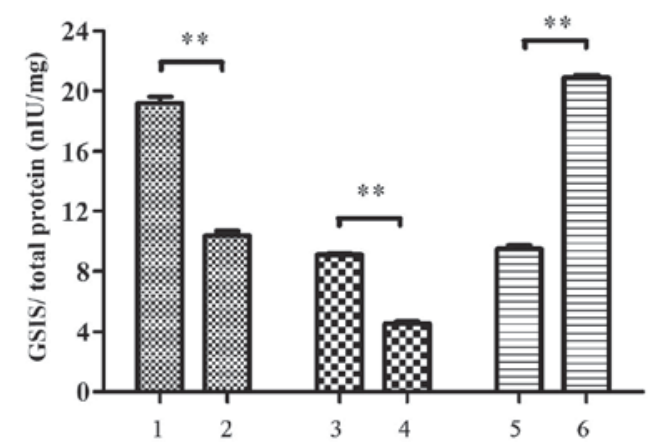

B

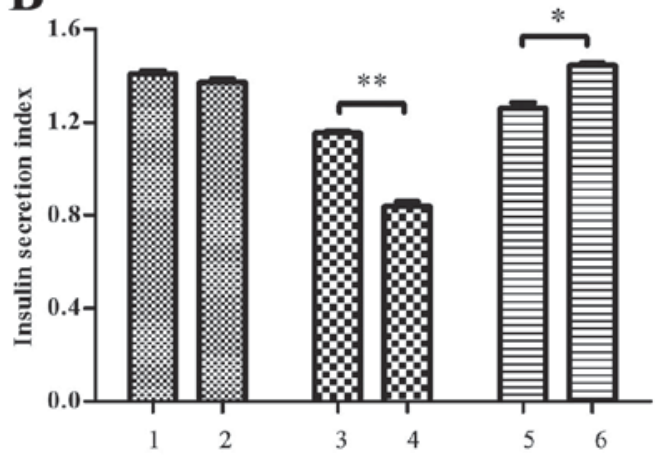

Figure 5. Conditioned media altered insulin secretion in MIN6 cells. MIN6 cells were incubated with conditioned media from RAW264.7 macrophage cultures and the level of insulin secretion (nIU/ml) in response to 2.8 and $25 \mathrm{mM}$ glucose (BIS and GSIS, respectively) was determined by ELISA. Total protein concentration $(\mathrm{mg} / \mathrm{ml})$ was used as a control. The ISI was derived as GSIS/BIS. Measurements of (A) GSIS and (B) ISI are shown. MIN6 cells were incubated with conditioned media obtained from the following: i) RAW264.7 cells treated with bovine serum albumin, ii) RAW264.7 cells treated with $500 \mu \mathrm{M}$ palmitate, iii) RAW264.7 cells transfected with pEGFP-N1 control plasmid, iv) RAW264.7 cells transfected with pEGFP-N1-RIP140, v) RAW264.7 cells transfected with scramble siRNA and vi) RAW264.7 cells transfected with RIP140 siRNA. Groups 3-6 were treated with $500 \mu \mathrm{M}$ palmitate post-transfection. Data are presented as the mean \pm standard deviation of three independent experiments. ${ }^{*} \mathrm{P}<0.05,{ }^{* *} \mathrm{P}<0.01$. MIN6 cells, murine pancreatic beta cell line; BIS, basal insulin secretion; GSIS, glucose-stimulated insulin secretion; ISI, insulin secretion index; siRNA, small interfering RNA.

Similar results were observed for the peritoneal macrophages isolated from c57BL/6 mice. Cell chemotaxis towards MIN6 cells was significantly increased by conditioned media from palmitate-treated MIN6 cells, with and without RIP140 overexpression, while chemotaxis was significantly decreased by conditioned media from palmitate-treated MIN6 cells with knockdown of RIP140, relative to their respective control groups ( $\mathrm{P}<0.01$; Fig. 8D).

TNF- $\alpha$ and IL- 6 concentration in the supernatant of MIN6 cells were also measured by ELISA following $500 \mu \mathrm{M}$ palmitate treatment. It was observed that levels of TNF- $\alpha$ and IL- 6 were significantly increased in the supernatant of palmitate-treated MIN6 cells $(\mathrm{P}<0.01$ and $\mathrm{P}<0.05$, respectively) and in that of palmitate-treated cells overexpressing RIP140 (both $\mathrm{P}<0.05$ ), relative to their respective control groups. By contrast, TNF- $\alpha$ and IL- 6 were significantly decreased in the supernatant of palmitate-treated, RIP140-knockdown MIN6 cells, relative to control cells $(\mathrm{P}<0.05$ and $\mathrm{P}<0.01$, respectively; Fig. $8 \mathrm{E}$ and $\mathrm{F})$.

\section{Discussion}

Inflammation is involved in insulin resistance within adipose and muscular tissue, thus promoting the onset of type II diabetes (26). In addition, pancreatic beta cell dysfunction serves a key role in pathophysiology of type II diabetes (27). However, whether crosstalk between macrophages and beta cells, with involvement of nuclear receptor cofactor RIP140, contributes to the onset of diabetes remains unknown. Previous results suggest that loss of RIP140 impairs inflammatory responses mediated by TLRs. RIP140 is considered to provide a platform for the stabilization of the NF- $\mathrm{KB}$ cofactors, RelA, and $\mathrm{CBP}$, thus regulating the expression of pro-inflammatory cytokines, including TNF- $\alpha$, IL-1 $\beta$ and IL-6 (19). In turn, high levels of inflammatory cytokines may disturb beta cell function and proliferation (28). The results of the present study suggested that the level of TNF- $\alpha$ and IL-6 expression in macrophages was increased by upregulation of RIP140 in the presence of palmitate, and that higher levels of TNF- $\alpha$ and IL-6 triggered an inflammatory response, thus contributing to decreased cell viability and insulin secretion of beta cells. These findings indicate the effects of macrophage-derived cytokines on beta cell function and the involvement of RIP140. Specifically, RIP140 may promote the release of inflammatory cytokines under lipotoxic conditions, thus accelerating beta cell failure.

In the present study, under high palmitate conditions, conditioned media derived from macrophages with and without RIP140 overexpression were able to activate JNK and ERK1/2 signaling. Phosphorylation of JNK and ERK1/2 serve important roles in cell signal transduction events, including gene transcription, proliferation, apoptosis, differentiation and insulin signaling (29). In addition, it has been observed that palmitate activates the phosphorylation of ERK1/2 and p38 mitogen-activated protein kinase pathways and endoplasmic reticulum stress in cell such as skeletal muscle and mesenchymal stem cells (30). A number of inflammatory cytokines, including IL- $1 \beta$, IFN- $\gamma$ and TNF- $\alpha$, are considered to be activators of JNK and ERK1/2 signaling, which may lead to an increase in the levels of reactive oxygen species and compensatory generation of nitric oxide (31). Collectively, these data suggest that the high levels of inflammatory mediators identified in the conditioned media of palmitate-treated and RIP140-upregulated macrophages may have disturbed beta cell signal transduction and proliferation, thus contributing to a decrease in insulin secretion. However, the mechanistic involvement of JNK and ERK1/2 is not fully understood and studies evaluating their pharmacological inhibition are warranted.

High levels of inflammatory cytokines may also affect the transcription of specific genes, including PGC- $1 \alpha$, UCP-2, iNOS1, PEPCK, PDX-1 and PCNA. As a transcriptional activator, PGC- $1 \alpha$ interacts with RIP140 and upregulates the expression of genes associated with mitochondrial metabolism (32). UCP-2 is a ubiquitously expressed mitochondrial carrier protein that uncouples the respiratory chain from ATP synthesis (33), with increases in UCP-2 possibly involved in reduced insulin secretion during oxidative stress (34). iNOS1 stimulates L-arginine to generate 
A

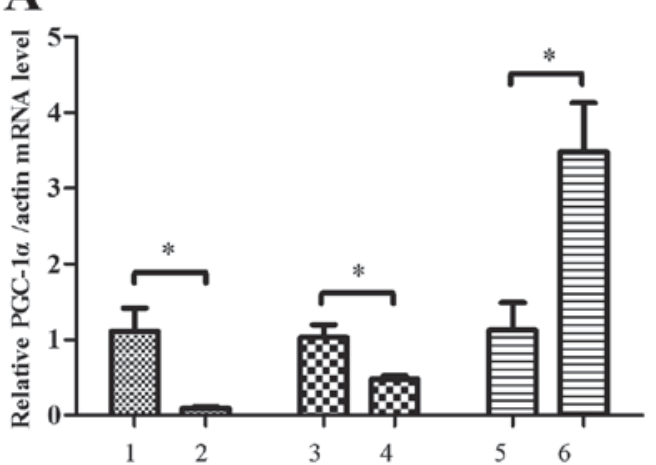

C

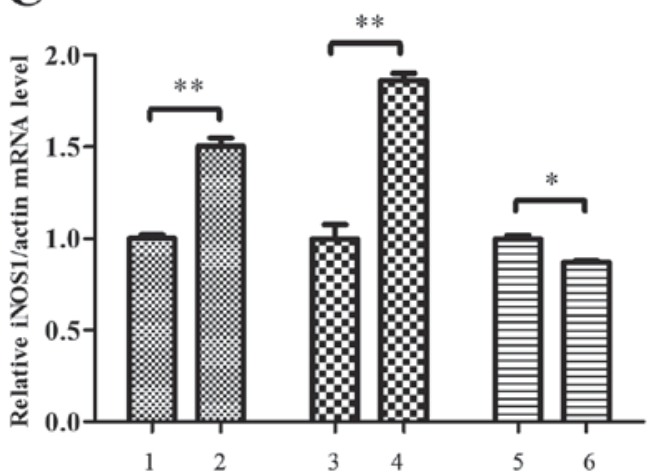

E

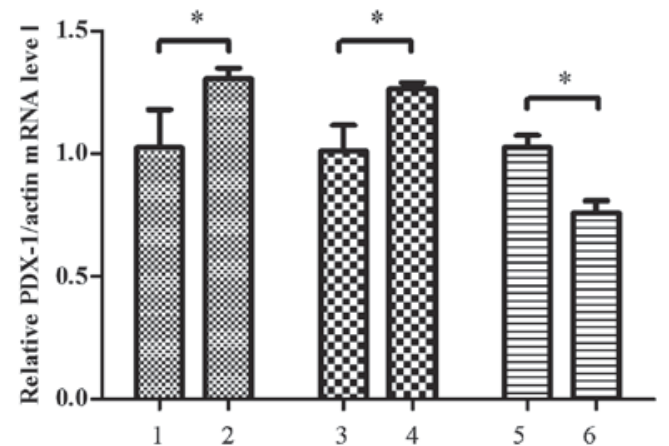

B

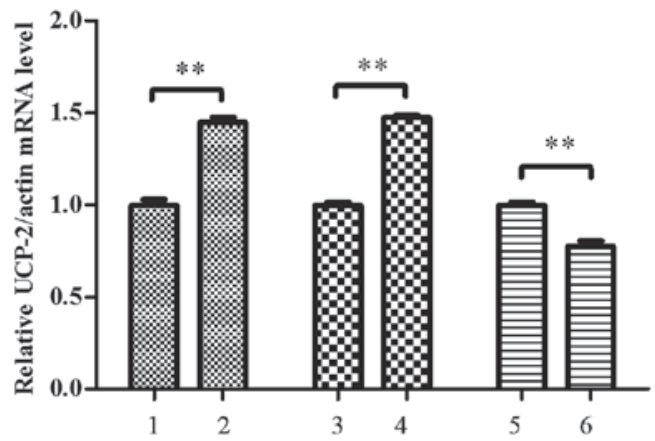

D

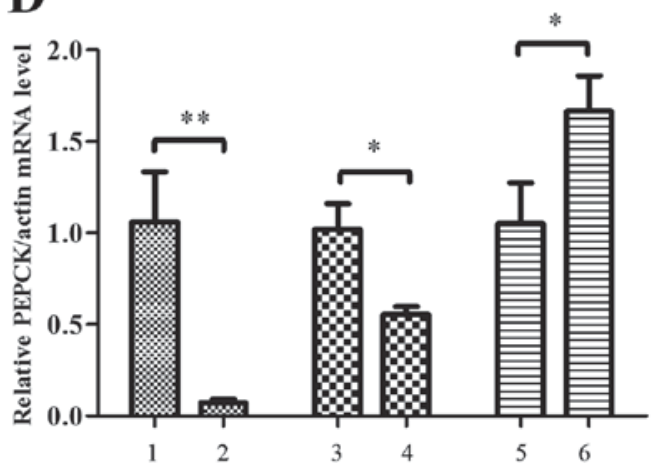

F

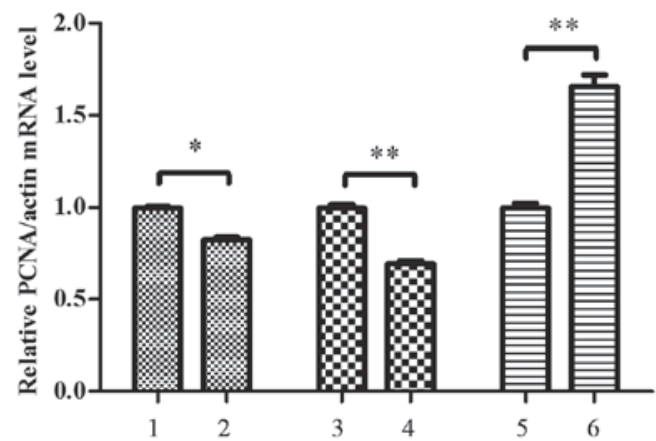

Figure 6. Conditioned media altered the expression of oxidative-stress related genes in MIN6 cells. MIN6 cells were treated with conditioned media from RAW264.7 macrophage cultures and the levels of (A) PGC-1 $\alpha$, (B) UCP-2, (C) iNOS-1, (D) PEPCK, (E) PDX-1 and (F) PCNA mRNA expression in MIN6 cells were determined by semiquantitative reverse transcription polymerase chain reaction. MIN6 cells were incubated with conditioned media obtained from the following: i) RAW264.7 cells treated with bovine serum albumin, ii) RAW264.7 cells treated with $500 \mu \mathrm{M}$ palmitate, iii) RAW264.7 cells transfected with pEGFP-N1 control plasmid, iv) RAW264.7 cells transfected with pEGFP-N1-RIP140 plasmid, v) RAW264.7 cells transfected with scramble siRNA and vi) RAW264.7 cells transfected with RIP140 siRNA. Groups 3-6 were treated with $500 \mu \mathrm{M}$ palmitate post-transfection. Data are presented as the mean \pm standard deviation of three independent experiments. ${ }^{*} \mathrm{P}<0.05,{ }^{* *} \mathrm{P}<0.01$. MIN6, murine pancreatic beta cell line; PPAR $\gamma$ coactivator $1 \alpha$; UCP-2, uncoupling protein 2; iNOS1, nitric-oxide synthase 1; PEPCK, phosphoenulpyruvate carboxykinase; PDX-1, pancreatic and duodenal homeobox 1; PCNA, proliferating cell nuclear antigen; siRNA, small interfering RNA.

NO, inducing an inflammatory reaction (35). In the present study, it was demonstrated that conditioned media from palmitate-treated and RIP140-upregulated macrophages, consisting of high levels of TNF- $\alpha$ and IL- 6 , induced a significant decrease in the level of PGC- $1 \alpha$ mRNA and a significant increase in the levels of UCP-2 and iNOS1 mRNA. These results indicate that RIP140 in macrophages induces cytokine secretion, which may then alter beta cell function and increase oxidative reaction stress. It has been demonstrated that RIP140 is necessary for LXR-dependent expression of PEPCK (16), as a rate-limiting enzyme in gluconeogenesis. In the current study, conditioned media containing high TNF- $\alpha$ and IL-6 was found to decrease PEPCK expression, suggesting that inflammatory cytokines may contribute to carbohydrate metabolism disorder. Moore et al (36) demonstrated that palmitate reduces insulin secretion by downregulating the expression of the insulin transcription factors PDX-1 and MafA. In addition, it has been observed that LPS represses PDX-1 expression and insulin secretion by pathways involving TLR4 and $\mathrm{NF}-\kappa \mathrm{B}$ (37). In the present study, conditioned media from macrophages overexpressing RIP140 prior to palmitate exposure significantly decreased GSIS and ISI, by upregulating PDX-1 mRNA expression. Fontes et al (38) suggested that Per-ARNT-Sim kinase may be independent from the ERK1/2 pathway and have no effect on MafA expression, suggesting that $\geq 3$ independent signaling 
A

p-JNK

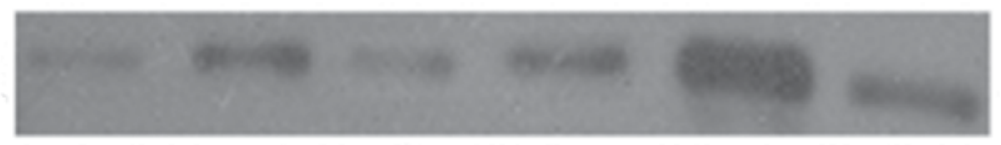

JNK

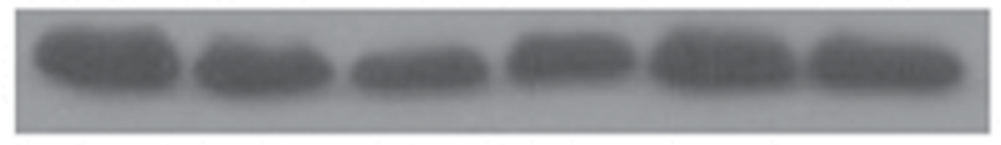

ERK1/2

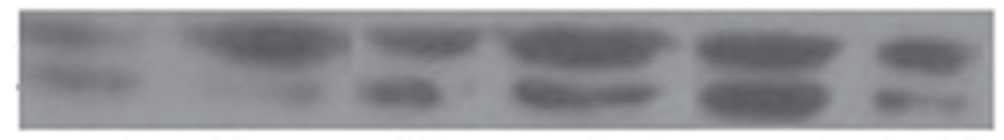

p-ERK1/2

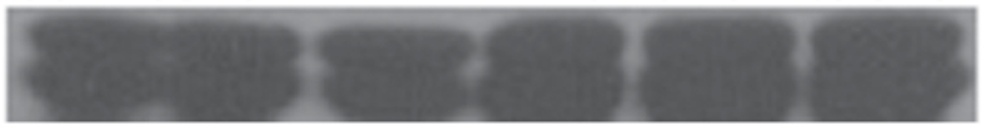

1

2

3

4

5

6
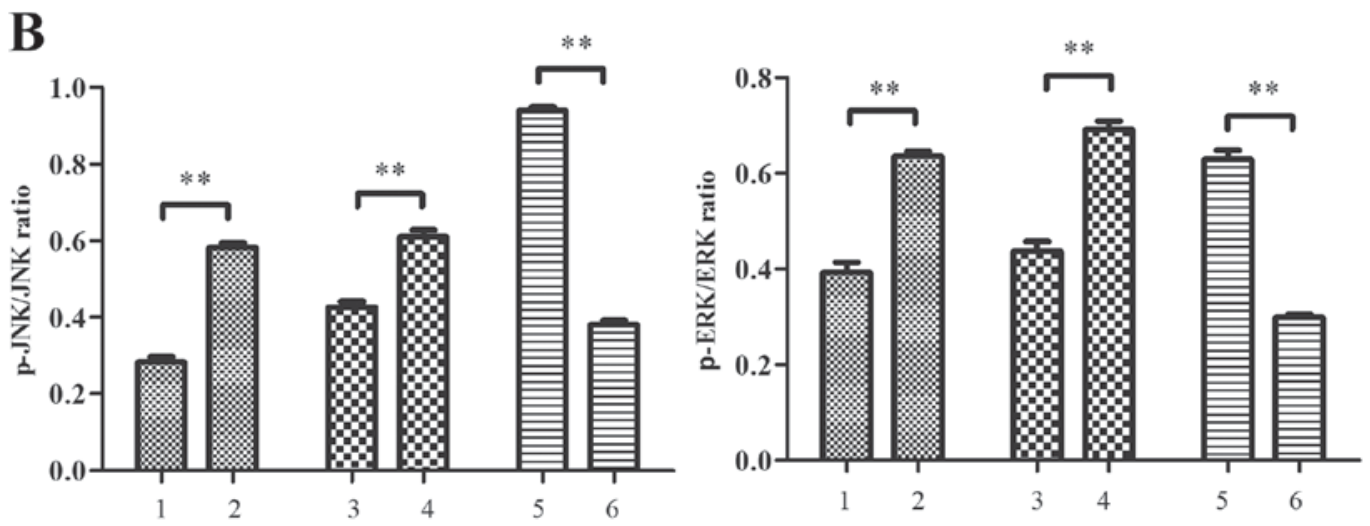

Figure 7. Conditioned media altered the levels of p-JNK and p-ERK1/2 in MIN6 cells. (A) Levels of p-JNK and p-ERK1/2 in MIN6 cells treated with conditioned media from RAW264.7 macrophages were determined by western blotting. (B) Relative protein levels were measured using AlphaEaseFC 4.0 software. MIN6 cells were incubated with conditioned media obtained from the following: i) RAW264.7 cells treated with BSA, ii) RAW264.7 cells treated with $500 \mu \mathrm{M}$ palmitate, iii) RAW264.7 cells transfected with pEGFP-N1 control plasmid, iv) RAW264.7 cells transfected with pEGFP-N1-RIP140 plasmid, v) RAW264.7 cells transfected with scramble siRNA and vi) RAW264.7 cells transfected RIP140 siRNA. Groups 3-6 were treated with $500 \mu$ M palmitate post-transfection. Data are presented as the mean \pm standard deviation of three independent experiments. ${ }^{* *} \mathrm{P}<0.01$. JNK, c-Jun N-terminal kinases; ERK, extracellular signal-regulated kinase; p-, phosphorylated; MIN6, murine pancreatic beta cell line; siRNA, small interfering RNA.

pathways may contribute to reduced insulin gene expression. Inflammatory cytokines may also affect PDX-1 expression by other pathways. In the current study, increasing levels of PDX-1 expression may have been a compensatory mechanism that occurred during stressful conditions, though insulin secretion did not increase accordingly and further study is warranted to verify this.

Macrophage infiltration of adipose and muscular tissue and hepatocytes may lead to peripheral insulin resistance (7-9). In the present study, chemotaxis assays were performed using Transwell plates. The conditioned media from MIN6 beta cells was added to the lower chamber and murine macrophages (peritoneal or RAW264.7) were added to the upper chamber. In assays of each cell type, cells migrated across the Transwell membrane, possibly due to the presence of a chemoattractant gradient. This is in accordance with the results of a previous study, in which the effects of a chemoattractant gradient were demonstrated by counting the number of macrophages on the lower surface of a Transwell membrane (39). In the present study, levels of TNF- $\alpha$ and IL-6 in the supernatant of MIN6 beta cells were significantly decreased by downregulation of RIP140 under high palmitate conditions, and the chemotaxis of RAW264.7 macrophages towards beta cells was reduced. By contrast, upregulation of RIP140 in beta cells under high palmitate conditions led to enhanced RAW264.7 macrophage chemotaxis and levels of TNF- $\alpha$ and IL- 6 in the supernatant were elevated. These results were analogous for peritoneal macrophages. Collectively, these findings suggest that RIP140 mediates inflammatory cytokine secretion in the presence of palmitate, which subsequently increases macrophage chemotaxis towards beta cells. However, macrophages are divided into two phenotypic categories: i) Anti-inflammatory (M2), which produce anti-inflammatory cytokines such as IL-10 and ii) pro-inflammatory (M1), which produce inflammatory cytokines such as IL- 6 and TNF- $\alpha$ (40). Therefore, a range of pro- and anti-inflammatory cytokines may be secreted in vivo. Therefore, the cumulative effects of inflammatory cytokines in vivo warrant further study.

In conclusion, the present study indicated that in high concentrations of palmitate, expression of RIP140 in macrophages stimulates the release of inflammatory cytokines, which may subsequently suppress beta cell viability and insulin secretion. The underlying mechanism remains 
A
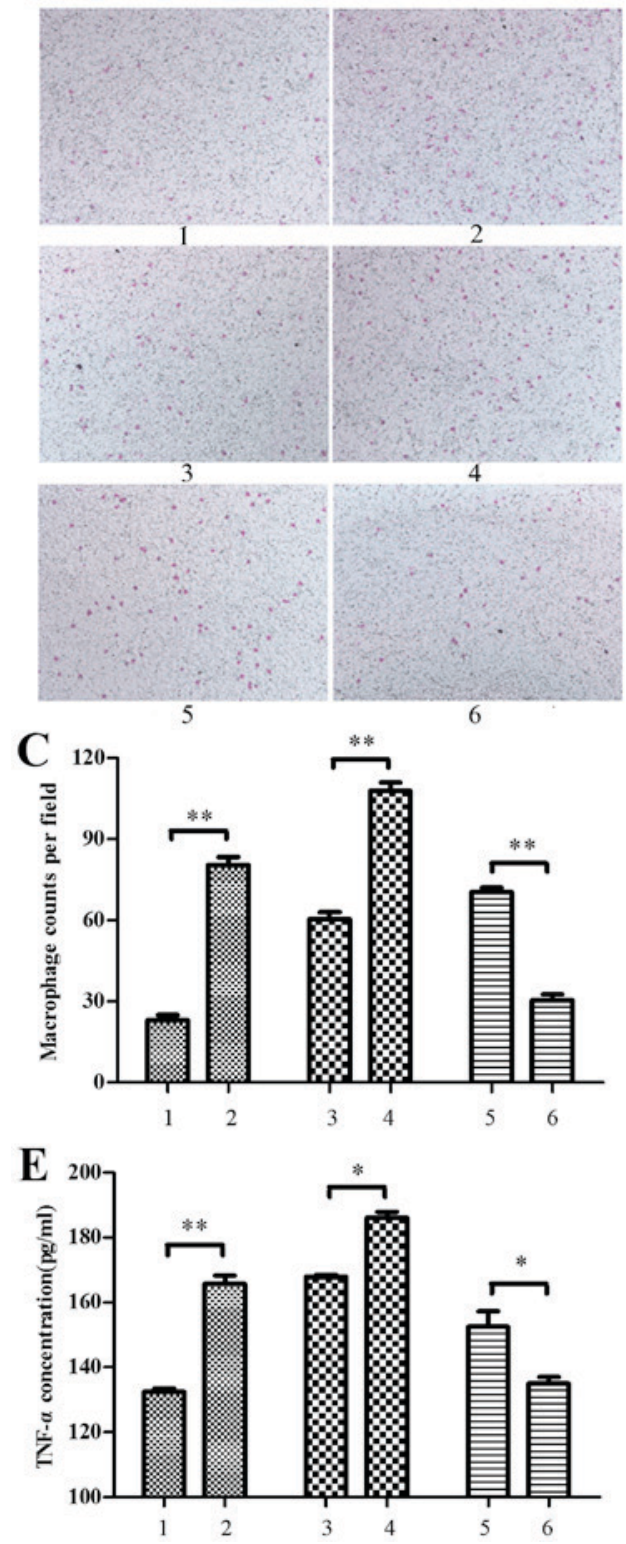

B
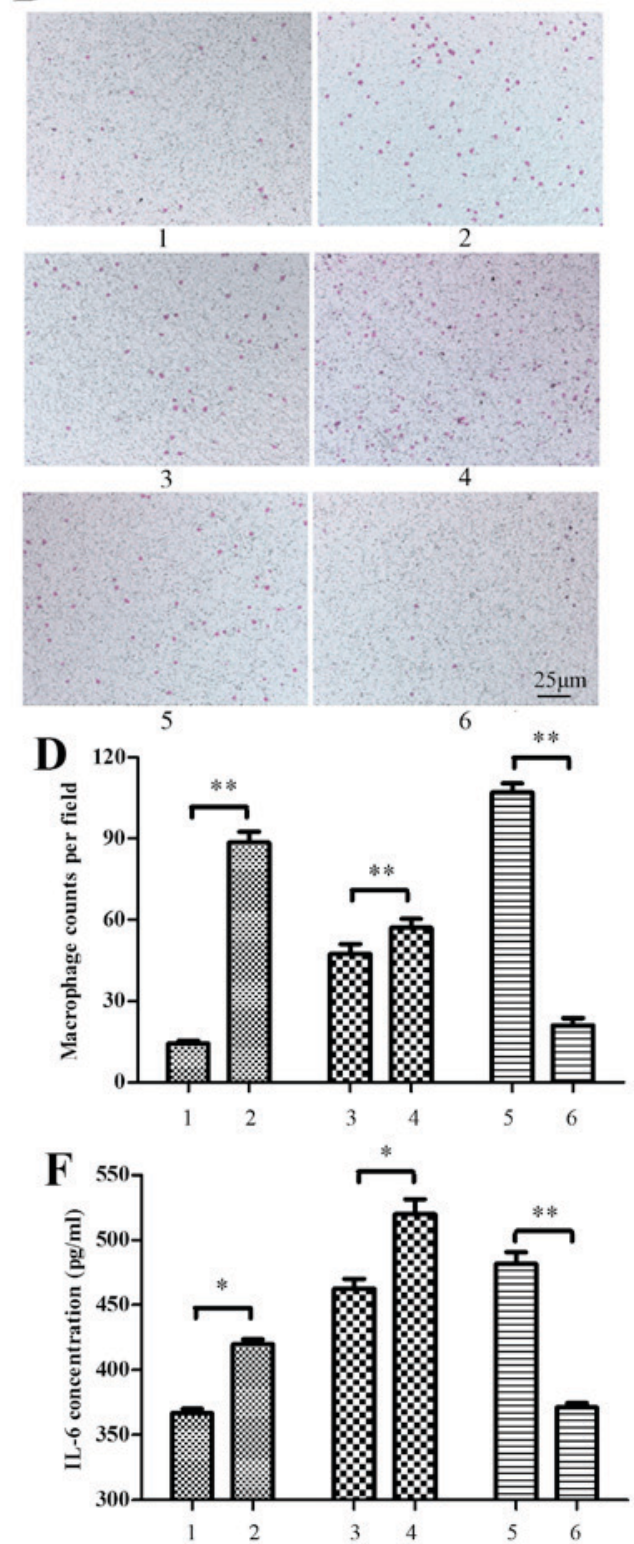

Figure 8. Macrophages chemotax towards MIN6 cells. Murine macrophages were treated with MIN6 cell culture supernatant for chemotaxis assays. (A) The RAW264.7 murine macrophage cell line and (B) peritoneal macrophages isolated from c57BL/6 mice were stained with crystal violet and viewed under a light microscope (magnification, x200). (C) RAW264.7 and (D) peritoneal macrophages were counted in six randomly selected fields. The concentration of (E) TNF- $\alpha$ and (F) IL-6 in the culture supernatant was also measured by ELISA. Supernatant for macrophage treatment was obtained from the following: i) MIN6 cells treated with bovine serum albumin, ii) MIN6 cells treated with $500 \mu \mathrm{M}$ palmitate, iii) MIN6 cells transfected with pEGFP-N1 control plasmid, iv) MIN6 cells transfected with pEGFP-N1-RIP140 plasmid, v) MIN6 cells transfected with scramble siRNA and vi) MIN6 cells transfected with RIP140 siRNA. Groups 3-6 were treated with $500 \mu \mathrm{M}$ palmitate post-transfection. Data are presented as the mean \pm standard deviation of three independent experiments. ${ }^{*} \mathrm{P}<0.05,{ }^{* *} \mathrm{P}<0.01$. MIN6, murine pancreatic beta cell line; TNF- $\alpha$, tumor necrosis factor- $\alpha$; IL-6, interleukin-6; siRNA, small interfering RNA.

unknown, though possibly involves regulation of specific gene expression and activation of JNK and ERK signaling. The present results also suggest that RIP140-mediated cytokine secretion under lipotoxic conditions may modulate macrophage chemotaxis towards beta cells. This may promote macrophage infiltration and local inflammation, ultimately leading to beta cell dysfunction.

\section{Acknowledgements}

The present study was supported by the National Natural Science Foundation of China (grant no. 81170769).

\section{References}

1. Xue J, Zhao H, Shang G, Zou R, Dai Z, Zhou D, Huang Q and $\mathrm{Xu}$ Y: RIP140 is associated with subclinical inflammation in type 2 diabetic patients. Exp Clin Endocrinol Diabetes 121: 37-42, 2013.

2. Solinas G, Vilcu C, Neels JG, Bandyopadhyay GK, Luo JL, Naugler W, Grivennikow S, Wynshaw-Boris A, Scadeng M, Olefsky JM and Karin M: JNK1 in hematopoietically derived cells contributes to diet-induced inflammation and insulin resistance without affecting obesity. Cell Metab 6: 386-397, 2007.

3. Nguyen MT, Favelyukis S, Nguyen AK, Reichart D, Scott PA, Jenn A, Liu-Bryan R, Glass CK, Neels JG and Olefsky JM. A subpopulation of macrophages infiltrates hypertrophic adipose tissue and is activated by free fatty acids via Toll-like receptors 2 and 4 and JNK-dependent pathways. J Biol Chem 282: 35279-35292, 2007. 
4. Nov O, Shapiro H, Ovadia H, Tarnovscki T, Dvir I, Shemesh E, Kovsan J, Shelef I, Carmi Y, Voronov E, et al: Interleukin-1 $\beta$ regulates fat-liver crosstalk in obesity by auto-paracrine modulation of adipose tissue inflammation and expandability. PLoS One 8: e53626, 2013.

5. Lumeng CN, Deyoung SM and Saltiel AR: Macrophages block insulin action in adipocytes by altering expression of signaling and glucose transport proteins. Am J Physiol Endocrinol Metab 292: E166-E174, 2007.

6. Varma V, Yao-Borengasser A, Rasouli N, Nolen GT, Phanavanh B, Starks T, Gurley C, Simpson P, McGehee RE Jr, Kern PA and Peterson CA: Muscle inflammatory response and insulin resistance: Synergistic interaction between macrophages and fatty acids leads to impaired insulin action. Am J Physio Endocrinol Metab 296: E1300-E1310, 2009.

7. KewalramaniG,Fink LN,AsadiF and Klip A:Palmitate-activated macrophages confer insulin resistance to muscle cells by a mechanism involving protein kinase $\mathrm{C} \theta$ and $\varepsilon$. PLoS One 6 : e26947, 2011.

8. Samokhvalov V, Bilan PJ, Schertzer JD, Antonescu CN and Klip A: Palmitate- and lipopolysaccharide-activated macrophages evoke contrasting insulin responses in muscle cells. Am J Physiol Endocrinol Metab 296: E37-E46, 2009.

9. Huang Y, Liu J, Xu Y, Dai Z and Alves MH: Reduction of insulin resistance in HepG2 cells by knockdown of LITAF expression in human THP-1 macrophages. J Huazhong Univ Sci Technolog Med Sci 32: 53-58, 2012.

10. Cunha DA, Hekerman $P$, Ladrière L, Bazarra-Castro A, Ortis F, Wakeham MC, Moore F, Rasschaert J, Cardozo AK, Bellomo E, et al: Initiation and execution of lipotoxic ER stress in pancreatic beta-cells. J Cell Sci 121: 2308-2318, 2008.

11. Fonseca SG, Gromada J and Urano F: Endoplasmic reticulum stress and pancreatic beta-cell death. Trends Endocrinol Metab 22: 266-274, 2011.

12. Cavailles V, Dauvois S, L'Horset F, Lopez G, Hoare S, Kushner PJ and Parker MG: Nuclear factor RIP140 modulates transcriptional activation by the estrogen receptor. EMBO J 14: 3741-3751, 1995

13. Docquier A, Garcia A, Savatier J, Boulahtouf A, Bonnet S, Bellet V, Busson M, Margeat E, Jalaguier S, Royer C, et al: Negative regulation of estrogen signaling by ERb and RIP140 in ovarian cancer cells. Mol Endocrinol 27: 1429-1441, 2013.

14. Leonardsson G, Steel JH, Christian M, Pocock V, Milligan S, Bell J, So PW, Medina-Gomez G, Vidal-Puig A, White R and Parker MG: Nuclear receptor corepressor RIP140 regulates fat accumulation. Proc Natl Acad Sci USA 101: 8437-8442, 2004.

15. Debevec D, Christian M, Morganstein D, Seth A, Herzog B, Parker $\mathrm{M}$ and White R: Receptor interacting protein 140 regulates expression of uncoupling protein 1 in adipocytes through specific peroxisome proliferator activated receptor isoforms and estrogen-related receptor alpha. Mol Endocrinol 21: 1581-1592, 2007.

16. Herzog B, Hallberg M, Seth A, Woods A, White R and Parker MG: The nuclear receptor cofactor, receptor-interacting protein 140, is required for the regulation of hepatic lipid and glucose metabolism by liver X receptor. Mol Endocrinol 21: 2687-2697, 2007.

17. Windahl SH, Treuter E, Ford J, Zilliacus J, Gustafsson JA and McEwan IJ: The nuclear-receptor interacting protein (RIP) 140 binds to the human glucocorticoid receptor and modulates hormone-dependent transactivation. J Steroid Biochem Mol Biol 71: 93-102, 1999.

18. Lee $\mathrm{CH}$ and Wei LN: Characterization of receptor-interacting protein 140 in retinoid receptor activities. J Biol Chem 274 31320-31326, 1999.

19. Zschiedrich I, Hardeland U, Krones-Herzig A, Berriel Diaz M, Vegiopoulos A, Müggenburg J, Sombroek D, Hofmann TG, Zawatzky R, Yu X, et al: Coactivator function of RIP140 for NFkappaB/RelA-dependent cytokine gene expression. Blood 112: 264-276, 2008.

20. Ho PC, Chang KC, Chuang YS and Wei LN: Cholesterol regulation of receptor-interacting protein 140 via microRNA-33 in inflammatory cytokine production. FASEB J 25: 1758-1766, 2011.

21. Ho PC, Tsui YC, Feng X, Greaves DR and Wei LN: NF- $\kappa \mathrm{B}$-mediated degradation of the coactivator RIP140 regulates inflammatory responses and contributes to endotoxin tolerance. Nat Immunol 13: 379-386, 2012.
22. Liu PS, Lin YW, Lee B, McCrady-Spitzer SK, Levine JA and Wei LN: Reducing RIP140 expression in macrophage alters ATM infiltration, facilitates white adipose tissue browning, and prevents high fat diet-induced insulin resistance. Diabetes 63 : 4021-4031, 2014

23. Dimopoulos N, Watson M, Sakamoto K and Hundal HS: Differential effects of palmitate and palmitoleate on insulin action and glucose utilization in rat L6 skeletal muscle cells. Biochem J 399: 473-481, 2006.

24. Gupta P, Ho PC, Huq MD, Khan AA, Tsai NP and Wei LN: PKCepsilon stimulated arginine methylation of RIP140 for its nuclear-cytoplasmic export in adipocyte differentiation. PLoS One 3: e2658, 2008

25. Kusminski CM, da Silva NF, Creely SJ, Fisher FM, Harte AL, Baker AR, Kumar S and McTernan PG: The in vitro effects of resistin on the innate immune signaling pathway in isolated human subcutaneous adipocytes. J Clin Endocrinol Metab 92: 270-276, 2007

26. Olefsky JM and Glass CK: Macrophages, inflammation, and insulin resistance. Annu Rev Physiol 72: 219-246, 2010.

27. Cernea $S$ and Dobreanu M: Diabetes and beta cell function: From mechanisms to evaluation and clinical implications. Biochem Med (Zagreb) 23: 266-280, 2013

28. Zhang S and Kim KH: TNF-alpha inhibits glucose-induced insulin secretion in a pancreatic beta-cell line (INS-1). FEBS Lett 377: 237-239, 1995.

29. Tanti JF and Jager J: Cellular mechanisms of insulin resistance: Role of stress-regulated serine kinases and insulin receptor substrates (IRS) serine phosphorylation. Curr Opin Pharmacol 9: 753-762, 2009.

30. Lu J, Wang Q, Huang L, Dong H, Lin L, Lin N, Zheng F and Tan J: Palmitate causes endoplasmic reticulum stress and apoptosis in human mesenchymal stem cells: Prevention by AMPK activator. Endocrinology 153: 5275-5284, 2012.

31. Seidelin JB and Nielsen OH: Continuous cytokine exposure of colonic epithelial cells induces DNA damage. Eur J Gastroenterol Hepatol 17: 363-369, 2005.

32. Chen Y, Wang Y, Chen J, Chen X, Cao W, Chen S, Xu S, Huang H and Liu P: Roles of transcriptional corepressor RIP140 and coactivator PGC-1 $\alpha$ in energy state of chronically infarcted rat hearts and mitochondrial function of cardiomyocytes. Mol Cell Endocrinol 362: 11-18, 2012.

33. Zhang CY, Baffy G, Perret P, Krauss S, Peroni O, Grujic D, Hagen T, Vidal-Puig AJ, Boss O, Kim YB, et al: Uncoupling protein-2 negatively regulates insulin secretion and is a major link between obesity, beta cell dysfunction, and type 2 diabetes. Cell 105: 745-755, 2001.

34. Li Y, Maedler K, Shu L and Haataja L: UCP-2 and UCP-3 proteins are differentially regulated in pancreatic beta-cells. PLoS One 3: e1397, 2008.

35. Chatterjee A, Black SM and Catravas JD: Endothelial nitric oxide (NO) and its pathophysiologic regulation. Vascul Pharmacol 49: 134-140, 2008.

36. Moore PC, Ugas MA, Hagman DK, Parazzoli SD and Poitout V: Evidence against the involvement of oxidative stress in fatty acid inhibition of insulin secretion. Diabetes 53: 2610-2616, 2004.

37. Amyot J, Semache M, Ferdaoussi M, Fontés G and Poitout V: Lipopolysaccharides impair insulin gene expression in isolated islets of Langerhans via Toll-Like Receptor-4 and NF- $\kappa$ B signalling. PLoS One 7: e36200, 2012

38. Fontes G, Semache M, Hagman DK, Tremblay C, Shah R, Rhodes CJ, Rutter J and Poitout V: Involvement of Per-Arnt-Sim Kinase and extracellular-regulated kinases-1/2 in palmitate inhibition of insulin gene expression in pancreatic beta-cells. Diabetes 58: 2048-2058, 2009.

39. Bruggeman LA, Drawz PE, Kahoud N, Lin K, Barisoni L and Nelson PJ: TNFR2 interposes the proliferative and $\mathrm{NF}-\kappa \mathrm{B}-$ mediated inflammatory response by podocytes to TNF- $\alpha$. Lab Invest 91: 413-425, 2011.

40. Antuna-Puente B, Feve B, Fellahi S and Bastard JP: Adipokines: The missing link between insulin resistance and obesity. Diabetes Metab 34: 2-11, 2008. 